\title{
Cardiopulmonary resuscitation is more effective for in- hospital cardiac arrest when performed on a stretcher
}

\author{
A manikin study
}

Onur Tezel, MD, Sedat Bilge, MD, Gökhan Özkan, MD.

\begin{abstract}

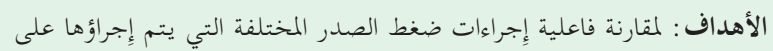

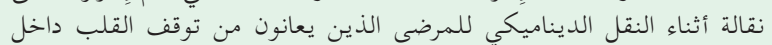
المستشفى.

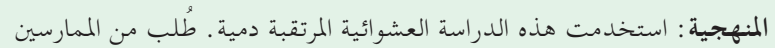

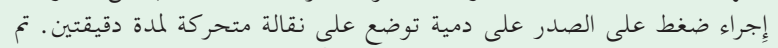

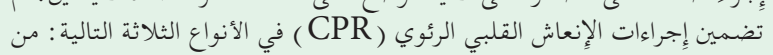

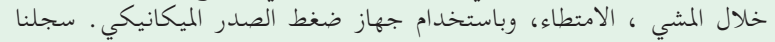

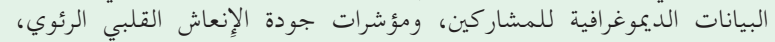

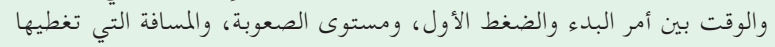
نقالة لمدة كل تطبيق البد

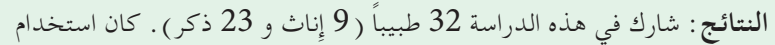

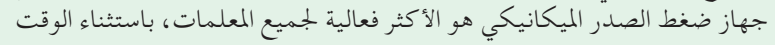

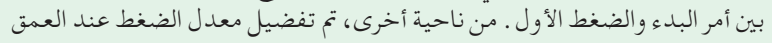

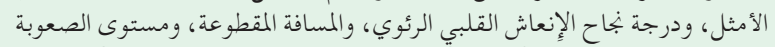

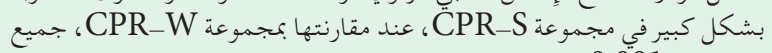
المقارنات، p p

الخلاصة : من الممكن إجراء ضغطات عالية الجودة على الصدر أثناء نقل المريض

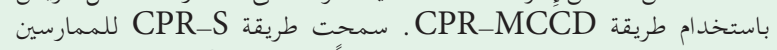
بإِجراء ضغطات أعلى جودة على الصدر مقارنةً بـ CPR_W. بـ طريقة
\end{abstract}

Objectives: To compare the efficacies of various chest compression procedures performed on a stretcher during dynamic transport of patients with in-hospital cardiac arrest.

Methods: This prospective and randomized cross-over study used manikins. Practitioners were asked to perform chest compressions on a manikin placed on a moving stretcher for 2 minutes. Cardiopulmonary resuscitation (CPR) procedures were included the following 3 types: i) CPR-walking (CPR-W) ii) CPR-straddling (CPR-S), and iii) CPR-mechanical chest compression device (CPR-MCCD). Demographic data of the participants, CPR quality indicators, the time between the start command and first compression, level of difficulty, and the distance covered by the stretcher for the duration of each application were recorded.
Results: Thirty-two physicians (9 female, 23 male), participated in this study. The CPR-MCCD procedure was the most effective for all parameters, except the time between the start command and first compression. On the other hand, the compression rate at optimal depth, CPR success score, distance covered, and level of difficulty parameters were significantly favored in the CPR-S group, when compared to the CPR-W group ( $p<0.001$, all comparisons).

Conclusions: It is possible to perform high-quality chest compressions during patient transport using the CPR-MCCD method. The CPR-S method allowed practitioners to perform higher-quality chest compressions compared to CPR-W.

Keywords: basic life support, cardiopulmonary resuscitation, external chest compressions, manikin, straddle

Saudi Med J 2021; Vol. 42 (1): 75-81 doi: 10.15537/smj.2021.1.25607

From the Department of Emergency Medicine (Tezel, Bilge) and from the Department of Anesthesiology and Reanimation (Özkan), Gulhane School of Medicine, University of Health Sciences, Ankara, Turkey.

Received 8th October 2020. Accepted 1st December 2020.

Address correspondence and reprint request to: Dr. Gökhan Özkan, Department of Anesthesiology and Reanimation, Health Sciences University, Gulhane Medical School, University of Health Sciences, Ankara, Turkey. E-mail:dr.gozkan@gmail.com

ORCID ID: http://orcid.org/0000-0002-7329-2492

$\mathrm{I}^{\mathrm{n}}$ n-hospital cardiac arrest (IHCA) can occur anywhere in the hospital, including the radiological imaging center, hallway, or cafeteria. Unlike outof-hospital cardiac arrest (OHCA), it is possible to treat reversible conditions that cause IHCA using advanced diagnosis and/or therapeutic options (such as catheter intervention in acute myocardial infarction). ${ }^{1}$ 
For this reason, patients must be transported to the emergency room or to a treatment room, where further diagnostic and therapeutic procedures can be performed. According to recommended guidelines, chest compressions should be performed without any interruption, if possible, at a depth of 5 to $6 \mathrm{~cm}$ by applying 100 to 120 compressions per minute, allowing recoil between compressions. ${ }^{2,3}$ If performed properly and in a suitable setting, chest compressions can result in adequate cerebral and myocardial perfusion. ${ }^{4}$ In most cases, patients are transported on a stretcher, making it difficult to perform effective chest compressions, even with a highly skilled and experienced resuscitation team. ${ }^{5,6}$ Previous studies have elucidated that manual chest compressions performed during transport are ineffective. $^{7-9}$ Updated guidelines list mechanical chest compression devices (MCCD) as an alternative for sustained cardiopulmonary resuscitation $(\mathrm{CPR})$ or $\mathrm{CPR}$ during transport. ${ }^{3}$ Previous research has also suggested that MCCD could be an alternative for manual chest compressions during transport. ${ }^{9,10}$ Studies regarding CPR during transport have mostly focused on OHCA; 6,9 therefore, there is a limited number of studies on IHCA cases. Furthermore, guidelines that allow practitioners to achieve the optimal chest compression quality have not been established.

Therefore, we used a simulation manikin during in-hospital transport to investigate the efficacy of 3 different chest compression methods, in regard to quality criteria listed in current CPR guidelines, distance covered, and the level of difficulty.

Methods. The Laerdal Resusci Anne QCPR manikin (Laerdal Medical GmbH, Stavanger, Norway), patient transport stretcher (length: $200 \mathrm{~cm}$; maximum weight capacity: $150 \mathrm{~kg}$ ) (Tautman KBB, Ankara, Turkey), and MCCD (LUCAS ${ }^{\circledast} 2$ Jolife, Lund, Sweden) were used, according to the instructions of the manufacturer.

This study was designed as a prospective and randomized cross-over study using manikins. The study was approved by the Gulhane Non-Interventional Research Ethics Board of the University of Health Sciences on October 8, 2019 (Meeting no: 2019/14 Decision number:19/326). The study was carried out between January 2 and January 10, 2020, in Gulhane Training and Research Hospital Emergency Room. All

Disclosure. Authors have no conflict of interests, and the work was not supported or funded by any drug company. interventions were made by 15 emergency medicine residents and 17 anesthesia residents. Before the study, practitioners were theoretically informed about the configuration and use of the MCCD for 60 minutes.

Informed consent was obtained from all individual participants included in the study.

Inclusion criteria for residents were residents who had basic life support, advanced cardiac life support, advanced trauma life support training, and at least one year of medical service experience.

In all procedures, the stretcher was led by 2 people other than the practitioner. Practitioners were asked to perform basic life support using 3 different procedures, as defined below. All chest compression applications were performed during dynamic patient transport. Before the application, all interventions were randomized using www.randomizer.org. ${ }^{11}$

Cardiopulmonary resuscitation-walking (CPR-W). The practitioner was asked to start performing chest compressions while walking along the stretcher upon the arrest (start) command given by the researcher. (A video showing the CPR-W procedure is also available or downloadable at https://bit.ly/2NS1kUQ).

Cardiopulmonary resuscitation-atraddling (CPR-S). External chest compressions were performed with the practitioner kneeling and their legs straddling the upper thighs of the manikin. The practitioner was asked to climb onto the stretcher and start performing chest compressions when the arrest (start) command was given by the researcher. (A video showing the CPR-S procedure is also available or downloadable at https:// bit.ly/2BYMHMW).

Cardiopulmonary resuscitation-mechanical chest compression device (CPR-MCCD). The practitioner was asked to place LUCAS $^{\bullet} 2$ on the manikin, at the command of the researcher. (A video showing the CPR-MCCD procedure is also available or downloadable at https://bit.ly/2YRMtAb).

The 2015 Guidelines for Resuscitation of the European Resuscitation Council (ERC) recommend that a CPR practitioner be changed every 2 minutes to prevent a decline in chest compression quality due to fatigue. ${ }^{3}$ Therefore, CPR was performed for a maximum of 2 minutes at one time. Furthermore, to ensure that participants were able to rest, breaks of at least 6 minutes were taken between procedures, based on a previous prospective manikin study of Shinci et al. ${ }^{12}$ The distance covered by the stretcher within 2 minutes (starting from the first chest compression) was measured in meters and recorded. Practitioners were asked to offer feedback about the level of difficulty of each application using 
the numeric rating scale (NRS), with $0=$ not difficult and $10=$ very difficult.

The following CPR quality indicators were measured by a SimPad tablet connected to the manikin by WLAN: compression rate at optimal depth (\%), optimal decompression rate (\%), compression rate per minute, total number of compressions, average compression depth $(\mathrm{mm})$, hands-off time $(\mathrm{sec})$, compression rate with correct hand placement (\%), and CPR success score $(\%)$.

Based on an alpha value of $0.05,80 \%$ power, an enrollment ratio of 1, a compression depth of $40.9 \mathrm{~mm}$ in Group 1 (CPR-W) and $51.3 \mathrm{~mm}$ in Group 2 (CPR-S), we calculated a minimum sample size of $18 .{ }^{12}$

Statistical analysis. The demographic data of the participants (age, gender, height, and weight), data recorded by SimPad, the level of difficulty of each application (using the NRS, with $0=$ not difficult and $10=$ very difficult), and the distance covered by the stretcher were transferred to Microsoft Excel (Microsoft Corporation, Redmond, Washington, USA). Collected data was then transferred to a computer and analyzed using the SPSS 22.0 (SPSS Statistics for Windows, Version 22.0. IBM Corp., Armonk, N.Y., USA) statistical program. For descriptive statistics, the frequency and percentage were used for discrete data, while the mean \pm standard deviation and median (range) were used for continuous variables. Chi-squared tests were performed to compare discrete variables between the groups, while the Mann-Whitney U and KruskalWallis tests were used to compare continuous variables. A $p<0.05$ was considered statistically significant for all analyses and all p-values were 2-tailed.

Results. A total of 32 physicians (9 female, 23 male), including emergency residents $(n=15)$ and anesthesiology and reanimation residents $(\mathrm{n}=17)$ volunteered to participate in the study. The mean age of participants was $29 \pm 3.81$ years, the mean height was $176.72 \pm 7.85 \mathrm{~cm}$, and the mean weight was $76.40 \pm$ $13.63 \mathrm{~kg}$.

Regarding the average compression depth, the CPR-S $(55.44 \pm 6.08 \mathrm{~mm})$ and CPR-MCCD $(56.25 \pm 0.95 \mathrm{~mm})$ procedures achieved the compression depth recommended by the ERC and AHA guidelines; there was not a significant difference between these 2 procedures ( $p=0.416$; Table 1 ). The average compression depth was significantly lower when using the CPR-W procedure $(45.28 \pm 10.52 \mathrm{~mm})$ compared to the other 2 procedures $(p=0.001$ when compared to CPR-S and

Table 1 - Comparison of parameters evaluated for all three procedures for all practitioners $(\mathrm{N}=32)$.

\begin{tabular}{|c|c|c|c|c|c|c|c|}
\hline Parameters & CPR-W & CPR-S & CPR-MCCD & $P$-value & $\begin{array}{c}\text { CPR-W } \\
\text { versus } \\
\text { CPR-S }^{\dagger}\end{array}$ & $\begin{array}{c}\text { CPR-W } \\
\text { versus } \\
\text { CPR- } \\
\text { MCCD }^{\dagger}\end{array}$ & $\begin{array}{l}\text { CPR-S } \\
\text { versus } \\
\text { CPR- } \\
\text { MCCD }^{\dagger}\end{array}$ \\
\hline $\begin{array}{l}\text { Time from start command to first } \\
\text { compression (sec) }\end{array}$ & $2.11 \pm 0.12$ & $5.77 \pm 0.53$ & $27.11 \pm 3.32$ & $<0.001$ & $<0.001$ & $<0.001$ & $<0.001$ \\
\hline Compression rate at optimal depth (\%) & $29.72 \pm 30.82$ & $60.53 \pm 36.14$ & $98.81 \pm 0.78$ & $<0.001$ & $<0.001$ & $<0.001$ & $<0.001$ \\
\hline Optimal decompression rate (\%) & $60.66 \pm 33.88$ & $68.28 \pm 36.42$ & $93.25 \pm 21.65$ & $<0.001$ & 0.279 & $<0.001$ & 0.001 \\
\hline Compression rate per minute & $123.72 \pm 22.54$ & $124.53 \pm 13.89$ & $101 \pm 0$ & $<0.001$ & 0.846 & 0.001 & $<0.001$ \\
\hline Total number of compressions (in 2 mins) & $244.16 \pm 46.08$ & $249.06 \pm 27.77$ & $202.03 \pm 0.97$ & $<0.001$ & 0.682 & 0.002 & $<0.001$ \\
\hline Average compression depth (mm) & $45.28 \pm 10.52$ & $55.44 \pm 6.08$ & $56.25 \pm 0.95$ & $<0.001$ & $<0.001$ & $<0.001$ & 0.416 \\
\hline Handsoff time (sec) & $0.25 \pm 0.51$ & $0.06 \pm 0.25$ & 0 & 0.009 & 0.071 & 0.005 & 0.154 \\
\hline $\begin{array}{l}\text { Compression rate in correct hand } \\
\text { placement }\end{array}$ & $73.19 \pm 34.00$ & $95.81 \pm 14.09$ & 100 & $<0.001$ & $<0.001$ & $<0.001$ & 0.041 \\
\hline CPR success score & $37.13 \pm 33.19$ & $71.59 \pm 22.11$ & $98.28 \pm 0.46$ & $<0.001$ & $<0.001$ & $<0.001$ & $<0.001$ \\
\hline Distance covered (meters) & $150.92 \pm 3.71$ & $197.77 \pm 1.99$ & $209.25 \pm 4.10$ & $<0.001$ & $<0.001$ & $<0.001$ & $<0.001$ \\
\hline $\begin{array}{l}\text { Level of difficulty (NRS } \\
0 \text { : not difficult to } 10 \text { : very difficult) }\end{array}$ & $8.44 \pm 1.11$ & $4.34 \pm 0.60$ & $2.97 \pm 0.74$ & $<0.001$ & $<0.001$ & $<0.001$ & $<0.001$ \\
\hline
\end{tabular}

*Kruskal Wallis Test, †Wilcoxon test, CPR: cardiopulmonary resuscitation, CPR-W: CPR-walking, CPR-S: CPR- straddling, CPR-MCCD: CPR-mechanical chest compression device, NRS: numerical rating scales, sec: second 
$p<0.001$ when compared to CPR-MCCD; Table 1 ). For compression rate with the correct hand placement, the lowest score was achieved in the CPR-W procedure $(73.19 \pm 34.00 \%)$; this score was significantly lower than that of the CPR-S $(95.81 \pm 14.09 \%)$ and CPR-MCCD $(100 \%)$ procedures $(p<0.001$, both comparisons; Table 1). Furthermore, there was a statistically significant difference between the 3 procedures for the time between the start command and first compression $(p<0.001)$. This time was the shortest when using the CPR-W procedure $(2.11 \pm 0.12 \mathrm{sec})$ and the longest when using the CPR-MCCD procedure $(27.11 \pm 3.32$ sec) (Table 1). The time in the CPR-S group $(5.77 \pm 0.53 \mathrm{sec})$ was significantly lower than that of the CPR-MCDD group ( $p<0.001$; Table 1$)$. There was a statistically significant difference between the groups when comparing the CPR success score $(p<0.001)$. The success score was the lowest with the CPR-W procedure $(37.13 \pm 33.19)$ and the highest with the CPR-MCCD procedure $(98.28 \pm 0.46)$ (Table 1$)$. The score achieved by the CPR-S procedure $(71.59 \pm 22.11)$ was significantly higher than that achieved by the CPR-W procedure $(p<0.001$; Table 1$)$.

When comparing the distance covered by the stretcher in 2 minutes, there was a statistically significant difference between the groups $(p<0.001)$. The distance covered was the shortest in the CPR-W group
$(150.92 \pm 3.71 \mathrm{~m})$ and the longest in the CPR-MCCD group $(209.25 \pm 4.10 \mathrm{~m})$ (Table 1$)$.

Significant differences were also seen when comparing the level of difficulty among the groups $(p<0.001$, both comparisons; Table 1$)$.

When comparing these 3 procedures for emergency residents (Table 2) and anesthesiology residents (Table 3), approximately we had similar results. The time from the start command to the first compression in the CPR-MCCD procedure was significantly longer in anesthesiology residents $(29.83+0.98 \mathrm{sec})$ than in emergency residents $(24.02+2.02 \mathrm{sec})(p<0.001)$. Furthermore, there were no other significant differences between these two resident groups (Table 4).

Discussion. The most important advantage of performing external chest compressions on a moving stretcher is the ability to transport the patient without interrupting chest compressions.

We found that the CPR-W procedure failed to meet the recommended guidelines for the average compression depth; this finding aligned with results from randomized manikin studies by Shinchi et al ${ }^{12}$ and Jansen et $\mathrm{al},{ }^{13}$ which compared the efficacies of the CPR-W and CPR-S methods during patient transport on a stretcher. We assessed the reasons why CPR-W chest compressions may not have been adequate. To

Table 2 - Comparison of parameters evaluated for all three procedures for emergency medicine residents ( $\mathrm{n}=15)$.

\begin{tabular}{|c|c|c|c|c|c|c|c|}
\hline Parameters & CPR-W & CPR-S & CPR-MCCD & $P$-value* & $\begin{array}{c}\text { CPR-W } \\
\text { versus } \\
\text { CPR-S }\end{array}$ & $\begin{array}{l}\text { CPR-W } \\
\text { versus } \\
\text { CPR- } \\
\text { MCCD }^{\ddagger}\end{array}$ & $\begin{array}{c}\text { CPR-S } \\
\text { versus } \\
\text { CPR-MCCD }^{\ddagger}\end{array}$ \\
\hline $\begin{array}{l}\text { Time from start command to first } \\
\text { compression }(\mathrm{sec})\end{array}$ & $2.09 \pm 0.14$ & $5.50 \pm 0.64$ & $24.02 \pm 2.02$ & $<0.001$ & $<0.001$ & $<0.001$ & $<0.001$ \\
\hline Compression rate at optimal depth (\%) & $29.73 \pm 25.83$ & $50.87 \pm 39.33$ & $98.87 \pm 0.74$ & $<0.001$ & 0.146 & $<0.001$ & 0.002 \\
\hline Optimal decompression rate (\%) & $60.33 \pm 34.06$ & $68.80 \pm 37.92$ & $87.13 \pm 31.00$ & 0.009 & 0.663 & 0.003 & 0.023 \\
\hline Compression rate per minute & $127.60 \pm 24.97$ & $125.60 \pm 16.20$ & $101 \pm 0$ & 0.002 & 0.884 & 0.020 & $<0.001$ \\
\hline Total number of compressions ( 2 mins) & $254.53 \pm 50.88$ & $251.60 \pm 32.22$ & $201.87 \pm 1.13$ & $<0.001$ & 0.885 & 0.027 & $<0.001$ \\
\hline Average compression depth (mm) & $46.26 \pm 5.74$ & $56.07 \pm 6.37$ & $56.20 \pm 1.08$ & $<0.001$ & 0.001 & $<0.001$ & 0.195 \\
\hline Handsoff time (sec) & $0.07 \pm 0.26$ & 0 & 0 & 0.368 & 0.317 & 0.317 & 1.000 \\
\hline $\begin{array}{l}\text { Compression rate in correct hand } \\
\text { placement }\end{array}$ & $69.20 \pm 38.84$ & $95.33 \pm 18.07$ & 100 & 0.001 & 0.008 & 0.001 & 0.317 \\
\hline CPR success score & $33.27 \pm 29.62$ & $65.13 \pm 24.52$ & $98.33 \pm 0.49$ & $<0.001$ & 0.004 & $<0.001$ & $<0.001$ \\
\hline Distance covered (meters) & $149.95 \pm 3.18$ & $197.64 \pm 2.28$ & $207.93 \pm 5.46$ & $<0.001$ & $<0.001$ & $<0.001$ & $<0.001$ \\
\hline $\begin{array}{l}\text { Level of difficulty (NRS } \\
0 \text { : not difficult - 10: very difficult) }\end{array}$ & $8.27 \pm 1.03$ & $4.13 \pm 0.64$ & $2.47 \pm 0.52$ & $<0.001$ & $<0.001$ & $<0.001$ & $<0.001$ \\
\hline
\end{tabular}

*Kruskal Wallis Test, ${ }^{*}$ Wilcoxon test, CPR: cardiopulmonary resuscitation, CPR-W: CPR-walking, CPR-S: CPR-straddling, CPR-MCCD: CPR-mechanical chest compression device, NRS: numerical rating scales, sec: second 
Resuscitation on a stretcher ... Tezel et al

Table 3 -Comparison of parameters evaluated for all 3 procedures for anesthesiology residents $(n=17)$.

\begin{tabular}{|c|c|c|c|c|c|c|c|}
\hline Parameters & CPR-W & CPR-S & CPR-MCCD & $P$-value* & $\begin{array}{c}\text { CPR-W } \\
\text { versus } \\
\text { CPR-S }\end{array}$ & $\begin{array}{c}\text { CPR-W } \\
\text { versus } \\
\text { CPR- } \\
\mathrm{MCCD}^{\ddagger}\end{array}$ & $\begin{array}{c}\text { CPR-S } \\
\text { versus } \\
\text { CPR- } \\
\text { MCCD }^{\ddagger}\end{array}$ \\
\hline $\begin{array}{l}\text { Time from start command to first } \\
\text { compression (sec) }\end{array}$ & $2.14 \pm 0.93$ & $6.01 \pm 0.25$ & $29,83 \pm 0.98$ & $<0.001$ & $<0.001$ & $<0.001$ & $<0.001$ \\
\hline Compression rate at optimal depth (\%) & $29.70 \pm 35.45$ & $69.06 \pm 31.82$ & $98.77 \pm 0.75$ & $<0.001$ & 0.001 & $<0.001$ & 0.019 \\
\hline Optimal decompression rate (\%) & $60.94 \pm 34.75$ & $73.19 \pm 35.48$ & $98.65 \pm 0.87$ & 0.005 & 0.316 & 0.002 & 0.019 \\
\hline Compression rate per minute & $120.29 \pm 20.31$ & $123.59 \pm 11.92$ & $101 \pm 0$ & $<0.001$ & 0.617 & 0.011 & $<0.001$ \\
\hline Total number of compressions (2 mins) & $235.00 \pm 40.73$ & $246.82 \pm 23.97$ & $202.18 \pm 0.81$ & $<0.001$ & 0.428 & 0.033 & $<0.001$ \\
\hline Average compression depth (mm) & $44.41 \pm 13.56$ & $54.88 \pm 5.95$ & $56.29 \pm 0.84$ & 0.019 & 0.028 & 0.008 & 0.889 \\
\hline Handsoff time (sec) & $0.41 \pm 0.62$ & $0.12 \pm 0.33$ & 0 & 0.016 & 0.102 & 0.008 & 0.151 \\
\hline $\begin{array}{l}\text { Compression rate in correct hand } \\
\text { placement }\end{array}$ & $76.70 \pm 29.87$ & $96.24 \pm 9.93$ & 100 & $<0.001$ & 0.010 & $<0.001$ & 0.074 \\
\hline CPR success score & $40.53 \pm 36.61$ & $77.29 \pm 18.66$ & $98.24 \pm 0.44$ & $<0.001$ & 0.006 & $<0.001$ & $<0.001$ \\
\hline Distance covered (meters) & $151.78 \pm 4.01$ & $197.88 \pm 1.76$ & $210.42 \pm 1.87$ & $<0.001$ & $<0.001$ & $<0.001$ & $<0.001$ \\
\hline $\begin{array}{l}\text { Level of difficulty (NRS = } \\
0: \text { not difficult - 10: very difficult) }\end{array}$ & $8.59 \pm 1.18$ & $4.53 \pm 0.51$ & $3.41 \pm 0.67$ & $<0.001$ & $<0.001$ & $<0.001$ & $<0.001$ \\
\hline
\end{tabular}

Table 4 - Comparison of emergency medicine and anesthesiology residents by CPR method

\begin{tabular}{|c|c|c|c|c|c|c|c|c|c|}
\hline Parameters & $\begin{array}{c}\text { CPR-W } \\
\text { EM residents } \\
\quad(n=15)\end{array}$ & $\begin{array}{l}\text { CPR-W } \\
\text { anesthesiology } \\
\text { residents } \\
(n=17)\end{array}$ & $P$-value* & $\begin{array}{c}\text { CPR-S } \\
\text { EM residents } \\
\quad(n=15)\end{array}$ & $\begin{array}{c}\text { CPR-S } \\
\text { anesthesiology } \\
\text { residents } \\
(\mathbf{n}=17)\end{array}$ & $P$-value* & $\begin{array}{l}\text { CPR-MCCD } \\
\text { EM residents } \\
\quad(n=15)\end{array}$ & $\begin{array}{l}\text { CPR-MCCD } \\
\text { anesthesiology } \\
\text { residents } \\
(n=17)\end{array}$ & $P$-value* \\
\hline $\begin{array}{l}\text { Time from start } \\
\text { command to first } \\
\text { compression (sec) }\end{array}$ & $2.09 \pm 0.14$ & $2.14 \pm 0.93$ & 0.186 & $5.50 \pm 0.64$ & $6.01 \pm 0.25$ & 0.26 & $24.02 \pm 2.02$ & $29,83 \pm 0.98$ & $<0.001$ \\
\hline $\begin{array}{l}\text { Compression rate at } \\
\text { optimal depth (\%) }\end{array}$ & $29.73 \pm 25.83$ & $29.70 \pm 35.45$ & 0.436 & $50.87 \pm 39.33$ & $69.06 \pm 31.82$ & 0.183 & $98.87 \pm 0.74$ & $98.77 \pm 0.75$ & 0.683 \\
\hline $\begin{array}{l}\text { Optimal decompression } \\
\text { rate }(\%)\end{array}$ & $60.33 \pm 34.06$ & $60.94 \pm 34.75$ & 0.821 & $68.80 \pm 37.92$ & $73.19 \pm 35.48$ & 0.448 & $87.13 \pm 31.00$ & $98.65 \pm 0.87$ & 0.827 \\
\hline $\begin{array}{l}\text { Compression rate per } \\
\text { minute }\end{array}$ & $127.60 \pm 24.97$ & $120.29 \pm 20.31$ & 0.345 & $125.60 \pm 16.20$ & $123.59 \pm 11.92$ & 0.416 & $101 \pm 0$ & $101 \pm 0$ & 1.0 \\
\hline $\begin{array}{l}\text { Total number of } \\
\text { compressions ( } 2 \text { mins) }\end{array}$ & $254.53 \pm 50.88$ & $235.00 \pm 40.73$ & 0.249 & $251.60 \pm 32.22$ & $246.82 \pm 23.97$ & 0.406 & $201.87 \pm 1.13$ & $202.18 \pm 0.81$ & 0.497 \\
\hline $\begin{array}{l}\text { Average compression } \\
\text { depth }(\mathrm{mm})\end{array}$ & $46.26 \pm 5.74$ & $44.41 \pm 13.56$ & 0.955 & $56.07 \pm 6.37$ & $54.88 \pm 5.95$ & 0.493 & $56.20 \pm 1.08$ & $56.29 \pm 0.84$ & 0.722 \\
\hline Handsoff time (sec) & $0.07 \pm 0.26$ & $0.41 \pm 0.62$ & 0.052 & 0 & $0.12 \pm 0.33$ & 0.177 & 0 & 0 & 1.0 \\
\hline $\begin{array}{l}\text { Compression rate in } \\
\text { correct hand placement }\end{array}$ & $69.20 \pm 38.84$ & $76.70 \pm 29.87$ & 0.782 & $95.33 \pm 18.07$ & $96.24 \pm 9.93$ & 0.411 & 100 & 100 & 1.0 \\
\hline CPR success score & $33.27 \pm 29.62$ & $40.53 \pm 36.61$ & 0.719 & $65.13 \pm 24.52$ & $77.29 \pm 18.66$ & 0.173 & $98.33 \pm 0.49$ & $98.24 \pm 0.44$ & 0.545 \\
\hline $\begin{array}{l}\text { Distance covered } \\
\text { (meters) }\end{array}$ & $149.95 \pm 3.18$ & $151.78 \pm 4.01$ & 0.212 & $197.64 \pm 2.28$ & $197.88 \pm 1.76$ & 0.777 & $207.93 \pm 5.46$ & $210.42 \pm 1.87$ & 0.428 \\
\hline $\begin{array}{l}\text { Level of difficulty (NRS } \\
0 \text { : not difficult - 10: very } \\
\text { difficult) }\end{array}$ & $8.27 \pm 1.03$ & $8.59 \pm 1.18$ & 0.424 & $4.13 \pm 0.64$ & $4.53 \pm 0.51$ & 0.077 & $2.47 \pm 0.52$ & $3.41 \pm 0.67$ & $<0.001$ \\
\hline
\end{tabular}


effectively perform chest compressions, both elbows must be stretched flat and the practitioner's shoulders must be right above the area where compressions are applied, as suggested by Shinchi et al. ${ }^{12}$ This way, pressure can be applied on the sternum vertically. Chest compressions are performed with the patient maintaining this posture. However, it is difficult for the practitioner to maintain this posture in CPR-W because he/she is required to walk while performing chest compressions. As a result, weight cannot be applied perpendicularly to the sternum. These are potential reasons why the adequate depth cannot be achieved using the CPR-W method. Since this was not the case in the CPR-S group, the recommended average compression depth was achieved; this finding aligned with the results of studies conducted by Shinchi et $\mathrm{al}^{12}$ and Jansen et al. ${ }^{13}$ An effective CPR depth was achieved using CPR-MCCD; this was also reported in a manikin study by Gassler et al. ${ }^{9}$ The study compared the effectiveness of the various types of MCDD and manual CPR while transporting patients on a helicopter.' A manikin study by Drinhaus et $\mathrm{al}^{14}$ compared the effectiveness of MCDD and manual CPR methods while transporting patients on a stretcher. Since there were no significant differences between the CPR-S and CPR-MCDD groups, the CPR-S method was found to be as effective as the CPR-MCDD group, especially in terms of compression depth.

Similar to a previous study, ${ }^{13}$ we found that the CPR-W and CPR-S methods did not allow for adequate chest expansion. We believe that this is because CPR practitioners tend to lean onto the chest, especially during CPR performed during transport; this phenomenon was also explained by Krasteva et al. ${ }^{15}$ Restricting chest expansion disrupts resuscitation quality and positive intrathoracic pressure, which is produced when full re-expansion of the chest is not allowed; therefore, restricting expansion of the chest must be avoided. ${ }^{2}$

For the CPR-S and CPR-W methods, the average number of compressions per minute was found to be higher than the numbers recommended in the ERC and AHA guidelines. Furthermore, Gassler et $\mathrm{al}^{9}$ and Ventzke et $\mathrm{al}^{10}$ found a significantly higher number of compressions per minute when comparing the efficacy of various MCCDs during patient transport. This was likely because it was difficult to concentrate on the number of compressions during dynamic patient transport. However, Lei et $\mathrm{al}^{6}$ compared the efficacy of standard CPR (performed on the ground) with that of the CPR-S method performed on a stretcher during patient transport; both the CPR-S and standard CPR groups were within the range recommended in the guidelines regarding the average number of compressions. This could be attributed to the use of a metronome during $\mathrm{CPR}$, as indicated in the study method. We believe that the use of MCCD is advantageous because the average number of compressions was constant and effective in the CPR-MCCD group.

However, like the studies conducted by Gassler et $\mathrm{al}^{9}$ and Ventzke et al, ${ }^{10}$ the time from the start command to the first compression was longer than 10 seconds in the CPR-MCCD group. Compared to anesthesiology residents, emergency residents took less time to prepare the device. We think that this is because emergency residents use MCCDs in their daily practices, while anesthesiology residents do not. However, even emergency residents took more than 10 seconds. The guidelines stress that interruptions should not exceed 10 seconds, even for invasive procedures; this is important for preventing interruption in circulation. ${ }^{3}$ Therefore, we think that the use of MCCDs during short-term transport is limited.

It is important to rapidly treat the reversible causes of cardiac arrest, such as myocardial infarction. Therefore, it is critical to transport a patient to other in-hospital areas, where such interventions are performed, as soon as possible. In our study, the CPR-S group covered more distance than the CPR-W group; this result aligned with the findings of Jansen et al. ${ }^{13}$ The longest distance was covered by the CPR-MCCD group, suggesting that this method could be the fastest way to get the patient to the desired treatment area. Nevertheless, when considering the time that is required to install the MCCD, the CPR-S method may be as time effective as the CPR-MCCD method.

One of the major concerns in chest compression performed during transport is that the quality of chest compressions may deteriorate due to disruptions caused by incorrect hand placement. ${ }^{9,12,13}$ In our study, we observed major disruptions in correct hand placement in the CPR-W group only; this finding aligned with results from studies by Jansen et $\mathrm{a}^{13}$ and Gassler et al. ${ }^{9}$

We believe that the differences in the level of difficulty and physician satisfaction were caused by the fact that the CPR-MCCD group had to exert additional effort after placing the MCCD. We also think that the CPR-S group performed better in terms of physician satisfaction and the level of difficulty compared to the CPR-W group because it was less exhausting and easier than CPR-W. These differences in difficulty were also reported by practitioners in a previous study. ${ }^{13}$ The level of difficulty of the CPR-MCDD procedure may 
have been higher for anesthesiology residents than emergency medicine residents because emergency medicine residents are more familiar with Lucas ${ }^{\oplus} 2$ and use it in their daily practices.

Study limitations. This study has a few limitations that should be addressed. First, this is a manikin study and a simulated scenario, meaning that the reenactment of reality is limited. Brain or cardiac perfusion scans cannot be performed on manikins. Factors affecting resuscitation, such as stress and fatigue, should be studied in the future during long periods of resuscitation.

In conclusion, our study revealed that it is possible to perform high quality chest compressions during in-hospital transport. The CPR-MCCD method met all criteria outlined in the current ERC and AHA guidelines for effective CPR. However, the CPR-S method enabled faster transport, allowed practitioners to perform higher-quality chest compressions and was considered effective and less exhaustive by practitioners. Therefore, we recommend using the CPR-S method while transporting in-hospital arrest cases, if MCCD is not available. We do not recommend using the CPR-W method because it did not meet the criteria of the ERC and AHA guidelines.

Acknowledgment. The authors gratefully acknowledge Editage (www.edditage.com) for English language editing.

\section{References}

1. Truhlár A, Deakin CD, Soar J, Khalifa GEA, Alfonzo A, Bierens JJLM, et al. European Resuscitation Council Guidelines for Resuscitation 2015. Section 4. Cardiac arrest in special circumstances. Resuscitation 2015; 95: 148-201.

2. Kleinman ME, Brennan EE, Goldberger ZD, Swor RA, Terry M, Bobrow BJ, et al. Part 5: Adult basic life support and cardiopulmonary resuscitation quality: 2015 American Heart Association guidelines update for cardiopulmonary resuscitation and emergency cardiovascular care. Circulation 2015; 132 (18 Suppl 2): 414-435.

3. Perkins GD, Handley AJ, Koster RW, Castrén M, Smyth MA, Olasveengen T, et al. European Resuscitation Council Guidelines for Resuscitation 2015. Section 2. Adult basic life support and automated external defibrillation. Resuscitation 2015; 95: 81-99.
4. Paradis NA, Martin GB, Goetting MG, Rosenberg JM, Rivers EP, Appleton TJ, et al. Simultaneous aortic, jugular bulb, and righ atrial pressures during cardiopulmonary resuscitation in humans. Insights into mechanisms. Circulation 1989; 80: 361-368.

5. Kim JA, Vogel D, Guimond G, Hostler D, Wang HE, Menegazzi JJ. A randomized, controlled comparison of cardiopulmonary resuscitation performed on the floor and on a moving ambulance stretcher. Prehosp Emerg Care 2006; 10: 68-70.

6. Lei Z, Qing H, Yaxiong Z. The efficacy of straddling external chest compression on a moving stretcher. Resuscitation 2010; 81: 1562-1565.

7. Sunde K, Wik L, Steen PA. Quality of mechanical, manual standard and active compression-decompression CPR on the arrest site and during transport in a manikin model. Resuscitation 1997; 34: 235-242.

8. Olasveengen TM, Wik L, Steen PA. Quality of cardiopulmonary resuscitation before and during transport in out-of-hospital cardiac arrest. Resuscitation 2008; 76: 185-190.

9. Gässler H, Kümmerle S, Ventzke MM, Lampl L, Helm M. Mechanical chest compression: an alternative in helicopter emergency medical services? Intern Emerg Med 2015; 10: 715-720.

10. Ventzke MM, Gässler H, Lampl L, Helm M. Cardio pump reloaded: In-hospital resuscitation during transport. Intern Emerg Med 2013; 8: 621-626.

11. Urbaniak GC. Plous S. Research Randomizer (Version 4.0) [Updated 2019. Cited 2013 June 22]. Available from: http:// www.randomizer.org/

12. Shinchi M, Kobayashi M, Soma K, Maeda A. Comparison of chest compression quality in walking versus straddling cardiopulmonary resuscitation during stretcher transportation: A prospective randomised crossover study using manikins. PLoS One 2019; 14: e0216739.

13. Jansen G, Kipker K, Latka E, Borgstedt R, Rehberg S. Highquality chest compressions are possible during intra-hospital transport, but depend on provider position: A manikin study. Eur Eur J Anaesthesiol 2020; 37: 286-293.

14. Drinhaus H, Nüsgen S, Adams N, Wetsch WA, Annecke T. Rescue under ongoing CPR from an upper floor: Evaluation of three different evacuation routes and mechanical and manual chest compressions: A manikin trial. Scand J Trauma Resusc Emerg Med 2020; 28: 16.

15. Krasteva V, Jekova I, Didon JP. An audiovisual feedback device for compression depth, rate and complete chest recoil can improve the CPR performance of lay persons during selftraining on a manikin. Physiol Meas 2011; 2011; 32: 687-699. 